\title{
Astean behineko intsulina egunean behineko intsulina bezain erabilgarria izan daiteke bigarren motako diabetesean
}

Icodec intsulinak (astean behin) Glargina intsulinaren antzeko hobekuntza lortzen du hemoglobina glikosilatuan $(-1,33$ vs -1.15$)$ hipogluzemia larrien tasa antzekoarekin $(0,53$ vs 0,46 hipogluzemia pertsonako eta urteko), baina hipogluzemia esanguratsu gehiagorekin (\% 16 vs $\% 10)$.

Gako-hitzak: diabetesa; intsulina; egunean behin; astean behin; hemoglobina glikosilatua; hipogluzemia; icodec; Glargina.

Once-weekly insulin can be as useful as once-daily insulin to treat Type 2 Diabetes

Icodec insulin (once-weekly) comparing to Glargine insulin has a similar glycated hemoglobin mean change (-1.33 vs -1.15) with a similar rate of severe hypoglycemic events $(0.53$ vs 0.46 events per patients-year), but with more clinically significant hypoglycemia (\% 16 vs \% 10).

Keywords: diabetes; insulin; once-weekly; once-daily; glycated hemoglobin; hypoglycemia; Icodec; Glargine

\section{Erreferentzia}

Rosenstock J, Bajaj HS, Janez A, Silver R, Begtrup K, Melissa VH, Jia T, Goldenberg R. Once-weekly insulin for type 2 diabetes without previous insulin treatment. N Engl J Med. 2020 November 383:2107-2116. doi: 10.1056/NEJMoa2022474.

\section{Kritikoki aztertutako testuaren egileak}

Asier Mitxelena Bengoetxea. Donostia Unib. Ospitalea. asier.mitxelenabengoetxea@osakidetza.eus

Beñat Zubeltzu Sese. Donostia Unibertsitateko Ospitalea. beñat.zubeltzusese@osakidetza.eus

\section{Galdera}

Pertsona (nori): bigarren motako diabetesa duen pertsona.

Interbentzioa (zer): astean behineko intsulina.

Konparazioa (zer): egunean behineko intsulina.

Helburua (zertarako): bizi-itxaropena; bizi-kalitatea; hemoglobina glikosilatua; hipogluzemia.

\section{Bilaketa}

Once-weekly insulin AND type 2 diabetes.

UpToDate; Dynamed; TripDataBase; Cochrane; Pubmed. 


\section{Ikerketaren ezaugarriak}

Ausazko saiakuntza kontrolatua. Bigarren fasea. 26 asteko iraupena. 247 gaixo guztira. 2 talde egin dira. 1:1 moduan banatu dira gaixoak tratamenduetara. Nazioarteko ikerketa da.

\section{Balorazio kritikoa}

1) Galdera argia? BAI

a) Gaixoak: 18-75 urte bitartekoak. Inoiz iraupen luzeko intsulina hartu gabeak. Azkeneko 180 egunetan 2. motako diabetesaren diagnosia egin zaienak.

b) Metforminaren dosi egonkorra dutenak; eta DPP4 inhibitzailea hartzen dutenak edo ez. Hemoglobina glikosilatua 7,0-9,5 artean dutenak.

c) Interbentzioa: Icodec intsulina astean behin, 70 unitaterekin hasita.

d) Konparazioa: Glargina intsulina egunean behin, 10 unitaterekin hasita.

e) Helburua: hemoglobina glikosilatuaren aldaketa hasieratik 26. astera; gluzemia baraualdian; pisua; azken bi asteetan jasotako intsulinaren unitate kopurua; albokalteak; hipogluzemiak.

2) Ausazko banaketa? BAl: hala dio artikuluak, baina ez da adierazten nola egin den (gehigarrietan ere ez).

3) Gaixoen jarraipena bukaeraraino? BAl. Emaitzen analisia tratatzeko asmoarekin egin da.

4) Tratamenduaren aldetik itsua? BAl: gaixoak eta medikuak.

5) Taldeak antzekoak ziren hasi aurretik? BAl.

6) Interbentzioaz gain beste desberdintasunik? EZ: intsulina egokitzeko algoritmoari jarraitu zaio.

\section{Emaitzak}

\begin{tabular}{|c|c|c|}
\hline & Icodec & Glargina \\
\hline HG hasieran & $\% 8,09$ & $\% 7,96$ \\
\hline HGaren diferentzia 26. astera & $-1,33$ & $-1,15$ \\
\hline HG <\% 7 duten gaixoak & $\% 72$ & $\% 68$ \\
\hline $\mathrm{HG}<\%$ 6,5 duten gaixoak & $\% 49$ & $\% 39$ \\
\hline Intsulina kopurua denera & $229 \mathrm{UI}$ & $284 \mathrm{UI}$ \\
\hline Albo-kaltea & $\% 52$ & $\% 51$ \\
\hline Albo-kalte esanguratsua & $\% 1,6$ & $\% 2,5$ \\
\hline Albo-kalte larria & $\% 0$ & $\% 0,8$ \\
\hline Hipogluzemia (edozein) & $\% 54$ & $\% 38$ \\
\hline Hipogluzemia esanguratsua & $\% 16$ & $\% 10$ \\
\hline Hipogluzemia larria & $\% 0,8$ & $\% 0$ \\
\hline
\end{tabular}

HG: hemoglobina glikosilatua

\section{Iruzkinak}

Enpresa farmazeutikoak finantzatutako ikerketa.

Enpresa farmazeutikoak parte hartu du ikerketaren diseinuan, datu-bilketan, analisian eta artikulua idazten.

Gaixo kopuru txikia: 247 (bigarren fasea). Hirugarren fasea egiteke dago. 